\title{
Identification of Glucitol (Sorbitol) and Ribitol in a Rust Fungus, Puccinia graminis f. sp. tritici
}

\author{
By D. J. MACLEAN* AND K. J. SCOTT* \\ Agricultural Research Council, Unit of Developmental Botany, \\ Huntingdon Road, Cambridge $C B_{3} \circ D Y$ \\ Department of Biochemistry, University of Queensland, \\ St Lucia, Queensland 4067, Australia
}

(Received I9 March 1976)

\begin{abstract}
SUMMARY
An examination of the soluble carbohydrates of the wheat stem rust fungus, Puccinia graminis Pers. f. sp. tritici Erikss. \& E. Henn., showed the presence of glucitol (sorbitol), ribitol, fructose, and traces of xylitol, as well as confirming the presence of mannitol, arabitol, trehalose, inositol and erythritol. Ribitol and glucitol were major components in glucose-grown mycelium, and appeared to be the major components in mycelium parasitic on wheat leaves, but not in germinated or ungerminated uredospores. It is suggested that glucitol and ribitol may be intermediates (or by-products) of glucose utilization, whereas mannitol, arabitol and trehalose represent storage carbohydrates.
\end{abstract}

\section{INTRODUCTION}

Rust fungi, in common with many other fungi, accumulate much of their carbon reserves as acyclic sugar alcohols (polyols). D-Mannitol and D-arabitol have been reported most commonly in fungi and, together with erythritol and glycerol, have been identified in germinated and ungerminated uredospores of the wheat stem rust fungus Puccinia graminis Pers. f. sp. tritici Erikss. \& E. Henn. (Prentice et al., 1959; Reisener et al., 1962). The presence of these polyols, together with the disaccharide trehalose, has been confirmed by many subsequent workers using paper and gas-liquid chromatography (e.g. Lewis \& Smith, I967a; Daly, Knoche \& Wiese, 1967; Mitchell \& Shaw, I968; Mitchell \& Roberts, 1973; Holligan et al., 1974). However, with one possible exception (Miersch, 1973), ribitol has not been identified as a product of the metabolism of glucose in fungi (Holligan \& Lewis, 1973) and glucitol has not been identified in rust fungi.

We have examined the soluble carbohydrates of vegetative mycelium (glucose-grown axenic cultures), and of germinated and ungerminated uredospores of Puccinia graminis tritici, and of wheat infected with this fungus; and have confirmed and extended a preliminary finding (Maclean, I97I) that the vegetative mycelium contains high concentrations of glucitol and ribitol.

* Present address: Department of Biochemistry, University of Queensland, St Lucia, Queensland 4067, Australia. 


\section{METHODS}

Growth of the fungus. Strains VIB, V3A and v3B isolated from race I26-Anz-6,7 of Puccinia graminis Pers. f. sp. tritici Erikss. \& E. Henn. were grown in Petri dishes on a cellulose film over medium IV solidified with agar, for 4 weeks at $23^{\circ} \mathrm{C}$ (Maclean, I974). Medium IV contained Czapek's mineral salts, I \% (w/v) peptone (Evans Medical, Speke, Liverpool), $4 \%(\mathrm{w} / \mathrm{v})$ D-glucose, $0.3 \%(\mathrm{w} / \mathrm{v})$ trisodium citrate, final $\mathrm{pH} 6.0$; no growth occurred if glucose was omitted from the medium. The mycelium was lifted from the cellophane surface and blotted gently with filter paper; about 0.5 to I $\mathrm{g}$ fresh wt $/ 9 \mathrm{~cm}$ Petri dish was obtained.

Preparation of uredospores and infected wheat. Puccinia graminis tritici race $2 \mathrm{I}$ (kindly supplied by Dr R. Johnson, Plant Breeding Institute, Cambridge) and 'Little Club' wheat were used. Uredial cultures were maintained on wheat as described by Williams, Scott \& Kuhl (I966). Uredospores were collected from infected plants on which pustules had been open for about one week; the uredospores were used for the extraction of carbohydrates or for the preparation of sporelings within one week of collection. Infected wheat for carbohydrate analysis was prepared by dusting the first leaf of six-day-old wheat with sufficient uredospores to form 80 or more pustules per leaf; the leaves were harvested 5 days later, at which stage the mycelium was just beginning to form a macroscopicallyvisible bulge beneath the abaxial epidermis of the leaves. Sporelings were prepared by germinating uredospores on distilled water $\left(2 \mathrm{ml} / \mathrm{mg}\right.$ uredospores) for $6 \mathrm{~h}$ at $2 \mathrm{I}{ }^{\circ} \mathrm{C}$ in the dark (Daly et al., 1967).

Preparation of neutral extracts for analysis of soluble carbohydrates. Healthy wheat leaves, rust-infected wheat leaves, and vegetative myceli umof the fungus were macerated with 10 or more vols of $80 \%(\mathrm{v} / \mathrm{v})$ ethanol for I min in a rotary-blade homogenizer, and the macerate was boiled for at least $10 \mathrm{~min}$. Uredospores and sporelings were boiled directly in $80 \%$ ethanol for $30 \mathrm{~min}$. All extracts were cooled, filtered, evaporated to dryness at 40 to $50^{\circ} \mathrm{C}$ in a rotary evaporator, dissolved in water, extracted with chloroform, and the aqueous fraction was deionized by shaking with a mixed resin (Amberlite IRA-400 bicarbonate form, Zeokarb 225 hydrogen form). The cleared extract was evaporated to dryness, weighed and made up to a known volume with water.

Paper chromatography. All chromatography was carried out on Whatman 3MM paper ( $56 \mathrm{~cm}$ long) which had previously been washed by descending chromatography using distilled water $(24 \mathrm{~h})$ followed by absolute ethanol $(24 \mathrm{~h})$, and then dried. Depending on the resolution required, descending chromatograms were developed for up to $80 \mathrm{~h}$ in the solvent systems described in Table I (Hough \& Jones, 1962; Lewis \& Smith, 1967 b; Holligan \& Lewis, 1973).

Detection of sugars and polyols on chromatograms. Aldoses were detected with an aniline hydrogen phthalate reagent (Nemec, Kefurt \& Jary, 1967) and ketoses (either free or combined) with a $p$-anisidine reagent (Lewis et al., 1972).

Aldoses, ketoses, oligosaccharides, and polyols were detected using an alkaline silver oxide method (Trevelyan, Procter \& Harrison, 1950), modified as follows to give even spot development. Silver nitrate reagent was prepared by dissolving I g silver nitrate in $3 \mathrm{ml}$ water, and adding $100 \mathrm{ml}$ aldehyde-free acetone. Potassium hydroxide reagent was prepared a few hours before use by mixing $5 \mathrm{ml} 10$ M-potassium hydroxide (aqueous) with $40 \mathrm{ml}$ absolute ethanol (AR grade), adding $55 \mathrm{ml}$ re-distilled diethyl ether, and allowing the solution to clear: the upper layer was used. Chromatograms were dipped in the silver nitrate reagent, allowed to dry for about Io min, dipped with an even motion in the potassium hydroxide 
Table I. Chromatographic mobility of carbohydrates in five solvent systems

Mobilities are expressed relative to the mobility of glucose $\left(R_{\mathrm{glu}}\right)$ in each solvent.

\begin{tabular}{lccccc} 
& \multicolumn{5}{c}{ Solvent system* } \\
Carbohydrate & A & B & C & E & F \\
$m$-Inositol & 0.33 & 0.16 & 0.12 & 0.19 & 0.37 \\
Trehalose & 0.26 & 0.10 & 0.10 & 0.25 & 0.60 \\
Sucrose & 0.46 & - & - & - & 0.77 \\
D-Glucose & $\mathrm{I} \cdot 00$ & $\mathrm{I} \cdot 00$ & $\mathrm{I} \cdot 00$ & $\mathrm{I} \cdot 00$ & $\mathrm{I} \cdot 00$ \\
Galactitol & $\mathrm{I} \cdot \mathrm{I} 8$ & 2.52 & $0.7 \mathrm{I}$ & smear & - \\
D-Mannitol & $\mathrm{I} \cdot 23$ & 2.65 & 0.86 & smear & - \\
D-Glucitol & $\mathrm{I} \cdot 19$ & $3 . \mathrm{I} 2$ & $0.8 \mathrm{I}$ & smear & - \\
D-Fructose & $\mathrm{I} \cdot 43$ & $\mathrm{I} \cdot 75$ & $\mathrm{I} \cdot 52$ & smear & - \\
Xylitol & $\mathrm{I} \cdot 90$ & 4.94 & $\mathrm{I} \cdot 40$ & 0.90 & - \\
D-Arabitol & $\mathrm{I} \cdot 90$ & 4.44 & $\mathrm{I} \cdot 55$ & $\mathrm{I} \cdot 25$ & - \\
Ribitol & $\mathrm{I} \cdot 90$ & 5.26 & $\mathrm{I} \cdot 84$ & $\mathrm{I} \cdot 85$ & $\mathrm{I} \cdot 27$ \\
Erythritol & 2.62 & 6.00 & 2.90 & 2.23 & $\mathrm{I} \cdot 48$
\end{tabular}

* Solvent A: ethyl acetate/acetic acid/formic acid/water (1 8:3:1:4, by vol.). Solvent B: ethyl methyl ketone/acetic acid/water saturated with boric acid at $20^{\circ} \mathrm{C}$ (9:I:I, by vol.). Solvent C: ethyl acetate/ pyridine/water (70:25:5, by vol.). Solvent E: ethyl acetate/pyridine/water saturated with boric acid at $20^{\circ} \mathrm{C}(60: 25: 10$, by vol.). Solvent F: iso-propanol/n-butanol/water (I4:2:4, by vol.).

reagent, and dried with a stream of air in a fume hood for 6 to $8 \mathrm{~min}$ to allow the spots to develop; the chromatograms were then soaked for $30 \min$ in $5 \%(w / v)$ sodium thiosulphate, washed in running water, and dried. All chromatograms developed in solvents containing boric acid were stained by the silver nitrate method after pretreatment with $4 \%(\mathrm{w} / \mathrm{v})$ hydrofluoric acid in acetone to remove the boric acid (Britton, 1959).

Strips cut from chromatograms stained by the silver method were quantified by using a transmission densitometer and measuring the area under the peak: results were within about $10 \%$ for duplicate samples, with a maximum loading of 5 to $30 \mu \mathrm{g}$ per spot depending on the sugar and the period of chromatographic development. Quantitative results were more accurate if the spot intensity was reduced by soaking the chromatogram for $\mathrm{I} h$ in $5 \%(\mathrm{w} / \mathrm{v})$ sodium thiosulphate acidified with acetic acid (to convert silver to silver sulphide) followed by washing and drying. Standards were run on all chromatograms.

Purification and isolation of polyols. Pentitols were initially separated from hexitols by applying bands ( $\mathrm{I}$ to $2 \mathrm{mg} \mathrm{cm} \mathrm{m}^{-1}$ or less) of cleared extract to sheets of washed Whatman $3 \mathrm{MM}$ paper and developing for 30 to $35 \mathrm{~h}$ in solvent $\mathrm{A}$; using the silver method polyols were located on strips cut from the chromatogram. Aldoses and ketoses were removed from the original cleared extract, and from the pentitol and hexitol fractions after the initial separation, by heating aqueous solutions with Amberlite IRA-400 resin (hydroxide form) for I5 to $20 \mathrm{~min}$; this treatment did not cause isomerization of polyols. The pentitol fraction was resolved by rechromatography with solvent $\mathrm{E}$, and the hexitol fraction by rechromatography with solvents B and C. After chromatography with solvents B or E, boric acid was removed as the volatile methyl ester by evaporating to dryness at $50^{\circ} \mathrm{C}$ four to five times after sequential additions of absolute methanol, followed by treatment with Amberlite IRA-400 (hydroxide form). It was often necessary to re-chromatograph preparations of some polyols, because the heavy loadings necessary for large-scale separations sometimes resulted in small but significant amounts of one polyol being 'carried' in a dense band of another polyol. Polyols were eluted from chromatograms with water.

Identification of polyols. Authentic polyols (from BDH and Sigma), and rust polyols 
tentatively identified by their chromatographic mobilities, were recrystallized from the following solvents: ribitol from ethanol, D-glucitol from methanol containing acetone, D-mannitol from aqueous methanol, D- and L-arabitol and xylitol from methanol, and galactitol from water. Infrared spectra were obtained from discs prepared by compressing mixtures of the polyol and potassium bromide; the discs were scanned with a Unicam SPI000 infrared spectrophotometer. The polyols listed above, except for D- and L-arabitol, were readily distinguished from each other by their infrared spectra.

\section{RESULTS}

Table 2 summarizes the sugars and polyols detected in extracts of various materials. Each component of a fraction gave the expected $R_{\text {glu }}$ value in at least two solvent systems (Table I) and gave the same reaction as authentic standards with specific stains.

\section{Identity of polyols in vegetative mycelium}

About $4 \%(\mathrm{w} / \mathrm{w})$ of the fresh wt of vegetative mycelium was recovered as soluble neutral compounds; this represents about $20 \%$ on a dry wt basis (mycelium is about $20 \%$ dry matter). The hexitol fraction from all strains (VIB, V3A, v3B) contained glucitol and mannitol but no trace of galactitol. The pentitol fractions contained mostly ribitol, with smaller arabitol components and traces of xylitol.

Fractionation of v3B mycelium yielded $10 \mathrm{mg}$ recrystallized mannitol, $20 \mathrm{mg}$ glucitol and Io $\mathrm{mg}$ ribitol; insufficient arabitol and xylitol were obtained for recrystallization. Recrysiallized compounds gave identical melting points to authentic compounds: ribitol 100 to IOI ${ }^{\circ} \mathrm{C}$, mannitol I 66 to $167^{\circ} \mathrm{C}$, glucitol sintered over the range 85 to I00 ${ }^{\circ} \mathrm{C}$. The infrared spectra of mycelial polyols and authentic standards were identical over the range 3500 to $625 \mathrm{~cm}^{-1}$, except for some very minor variations with mannitol which are attributed to traces of impurities or slight differences in the preparation of the potassium bromide discs. Although insufficient xylitol was obtained for physical measurements, both authentic and mycelial xylitol developed spots more rapidly than other pentitols when chromatograms were stained by the silver method.

\section{Polyols in healthy and rust-infected wheat}

Extracts of healthy and rust-infected wheat leaves were digested with hot Amberlite IRA-400 resin (hydroxide form) to remove aldoses and ketoses (glucose, fructose and minor monosaccharides) before analysis of the polyols. Rust-infected wheat contained considerably larger amounts of polyols than healthy wheat; low levels of compounds with the chromatographic mobilities of ribitol, arabitol and mannitol were detected on chromatograms very heavily loaded with extracts of healthy wheat, but these compounds could not be detected quantitatively in extracts of healthy leaves equivalent to the quantities used for analyses of infected leaves (Table 2). Presumably, the polyols in infected leaves were mostly of fungal origin.

In rust-infected wheat, the relative amounts of mannitol, glucitol, arabitol and ribitol as a percentage of total content of acyclic polyols were within the range found in two strains of the fungus ( $\left.\mathrm{V}_{1 \mathrm{~B}}, \mathrm{v}_{3} \mathrm{~B}\right)$ grown on glucose medium, except that the proportion of arabitol was somewhat higher in the infected wheat. This similarity of polyol proportions is consistent with the fungus having similar pathways of carbohydrate utilization whether growing parasitically on wheat, or axenically on glucose medium. 
Table 2. Soluble carbohydrates in Puccinia graminis f. sp. tritici

The carbohydrate content is expressed as $\mathrm{mg}(\mathrm{g} \text { fresh } \mathrm{wt})^{-\mathbf{1}}$.

\begin{tabular}{|c|c|c|c|c|c|c|}
\hline \multirow[b]{2}{*}{ Carbohydrate } & \multicolumn{2}{|c|}{$\begin{array}{l}\text { Glucose-grown } \\
\text { mycelium }\end{array}$} & \multirow[b]{2}{*}{$\begin{array}{c}\text { Infected } \\
\text { wheat }\end{array}$} & \multirow[b]{2}{*}{ Uredospores } & \multirow{2}{*}{\multicolumn{2}{|c|}{$\begin{array}{c}\text { Diffusates } \\
\text { from } \\
\text { Sporelings sporelings }\end{array}$}} \\
\hline & $\begin{array}{c}\text { Strain } \\
\text { VIB }\end{array}$ & $\begin{array}{c}\text { Strain } \\
\text { v3B }\end{array}$ & & & & \\
\hline Inositol & 0.12 & 0.16 & 0.06 & 0.7 & + & + \\
\hline Trehalose & $2 \cdot 4$ & $4 \cdot 6$ & $0.16 \dagger$ & $3 \cdot 8$ & + & $?$ \\
\hline Glucose & $1 \cdot 4$ & $4 \cdot 8$ & of & 0 & + & + \\
\hline Fructose & $I \cdot 3$ & $\mathrm{I} \cdot \mathrm{O}$ & ot & 0 & + & 0 \\
\hline Mannitol & 19.8 & $8 \cdot 8^{*}$ & 0.20 & 50 & + & + \\
\hline Glucitol & 4.5 & $15 \cdot 4^{*}$ & 0.29 & 0 & 0 & 0 \\
\hline Arabitol & $\mathrm{I} \cdot \mathrm{O}$ & 0.7 & 0.09 & $49 \cdot 5$ & + & + \\
\hline Ribitol & $\mathrm{I} \cdot 8$ & $6 \cdot 0^{*}$ & 0.16 & 0.5 & 0 & 0 \\
\hline Xylitol & trace & $\approx 0.14$ & 0 & trace(?) & 0 & 0 \\
\hline Erythritol & + & + & & + & & \\
\hline Total hexitol & $24 \cdot 3$ & $24 \cdot 2$ & 0.49 & 50 & & \\
\hline Total pentitol & $2 \cdot 8$ & $6 \cdot 7$ & 0.25 & 50 & & \\
\hline
\end{tabular}

+ , Present but amount not estimated; o, not detected (i.e. absent from the extract).

$*$ Identity confirmed by melting point and infrared spectrum; $\uparrow$ destroyed (or partially destroyed) by alkaline digestion.

\section{Polyols in uredospores, sporelings, and diffusates from sporelings}

The predominant polyols in preparations of germinated and ungerminated uredospores were mannitol and arabitol (Table 2). Ribitol was present as a very minor component of uredospores, but could not be detected in sporelings or diffusates from sporelings; glucitol could not be detected in any of these materials.

\section{DISCUSSION}

Ribitol, glucitol, and probably xylitol, can now be added to the list of acyclic polyols identified in rust fungi. The inability of other workers to detect these compounds in vegetative mycelium (e.g. plant material infected with a rust fungus) could be due to the failure of many chromatographic systems to separate the isomeric hexitols from each other, and the isomeric pentitols from each other. Ribitol and xylitol are both meso compounds; the glucitol is presumed to be the $\mathrm{D}$ form because D-glucitol (but not L-glucitol) has often been identified as a natural product (Touster \& Shaw, I962; Lewis \& Smith, 1967a); we did not isolate sufficient glucitol to determine its optical rotation. The presence of ribitol is of particular mycological interest, because previous reports of ribitol as a product of the metabolism of glucose in fungi have not been confirmed (Holligan \& Lewis, 1973), except for one possibly novel situation in a yeast which overproduces riboflavin (Miersch, 1973).

The precise role of free polyols in intermediary metabolism or parasitic associations of rust fungi is not understood (Lewis \& Smith, r967a; Smith, Muscatine \& Lewis, 1969). Whereas mannitol, arabitol and the disaccharide trehalose are present in both uredospores and vegetative mycelium, glucitol and ribitol are present in appreciable quantities only in vegetative mycelium. This suggests that glucitol and ribitol may be intermediates (or byproducts) of the uptake and utilization of exogenous carbohydrates such as glucose, and that mannitol, arabitol and trehalose represent reserve or storage carbohydrates. The presence of significant pools of fructose $(0.1 \%$ fresh wt, Table 2$)$ in glucose-grown mycelium 


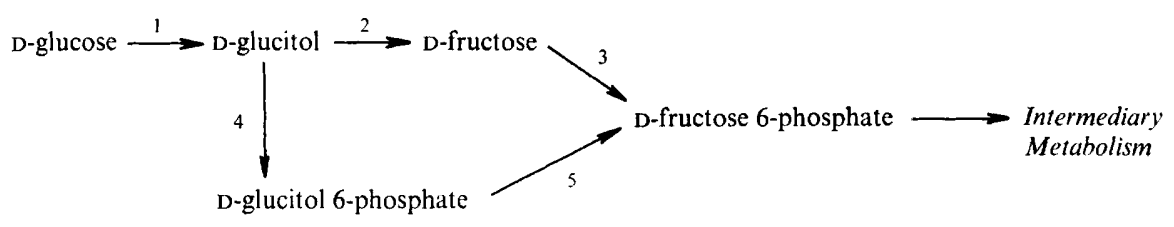

Fig. I. Possible scheme(s) for the uptake and utilization of glucose by Puccinia graminis f. sp. tritici

is consistent with a pathway for the conversion of glucose to fructose via non-phosphorylated intermediates, as is known in some animal systems (Hers, 1960; Touster \& Shaw, 1962). A possible scheme for the uptake and utilization of glucose by rust fungi (Fig. I) shows D-glucitol as the first product of glucose utilization, followed by two alternative pathways to fructose 6-phosphate. Preliminary studies on cell-free extracts provide evidence for reaction I (NADP-dependent oxidation of D-glucitol), reaction 2 (slow NAD-dependent oxidation of D-glucitol) (Maclean, 197I), and reaction 5 (NADH-dependent reduction of fructose 6-phosphate) (Hendrix, Daly \& Livne, 1964). Further work is required to define clearly enzyme systems which may participate in the above scheme and to follow the incorporation of labelled substrates into metabolic intermediates by the living fungus.

Note added in proof: Since this work went to press, we have become aware of the work of McComb \& Rendig (1970), who found that D-mannitol produces polymorphic crystals which differ in infrared spectra and X-ray powder patterns. The differences we observed between the infrared spectra of mannitol isolated from the rust fungus, and the spectra of authentic D-mannitol, are presumably due to differences in the relative proportion of each crystal type after each recrystallization, or after various periods of storage prior to running spectra.

D. J. M. is grateful to Professor P. W. Brian for support. Financial assistance from the Australian Research Grants Committee and the Wheat Industry Research Council of Australia is gratefully acknowledged.

\section{REFERENCES}

BRITTON, H. G. (1959). The detection of carbohydrates with silver in the presence of borate. Biochemical Journal 73, $19 \mathrm{P}$.

DALY, J. M., KNOCHE, H. W. \& WiESE, M. V. (I967). Carbohydrate and lipid metabolism during germination of uredospores of Puccinia graminis tritici. Plant Physiology 42, 1633-1642.

Hendrix, J. W., Daly, J. M. \& Livne, A. (1964). Pyridine nucleotide linked enzymatic reduction of triose pentose and hexose phosphates associated with rust infections. Phytopathology 54, 895 .

Hers, H. G. (1960). Le mécanisme de la formation du fructose séminal et du fructose foetal. Biochimica et biophysica acta 37, $127-138$.

Holligan, P. M., Chen, C., MCGee, E. E. \& Lewis, D. H. (1974). Carbohydrate metabolism in healthy and rusted leaves of coltsfoot. New Phytologist 73, 88I-888.

Holligan, P. M. \& LEWIS, D. H. (1973). The soluble carbohydrates of Aspergillus clavatus. Journal of General Microbiology 75, I 55-1 59.

Hough, L. \& JoNES, J. K. N. (I962). Chromatography on paper. In Methods in Carbohydrate Chemistry, vol. I, pp. 2I-3I. Edited by R. L. Whistler and M. L. Wolfrom. New York and London: Academic Press.

Lewis, D. H., Chen, C., Woods, G. \& Culpin, L. A. (1972). A modified p-anisidine technique for the detection and permanent recording of free and combined fructose on paper chromatograms. Journal of Chromatography 74, 369-372.

LewIS, D. H. \& SMITH, D. C. (1967a). Sugar alcohols (polyols) in fungi and green plants. I. Distribution, physiology and metabolism. New Phytologist 66, I43-I 84 .

LEwIS, D. H. \& SMITH, D. C. (I967 b). Sugar alcohols (polyols) in fungi and green plants. II. Methods of detection and quantitative estimation in plant extracts. New Phytologist 66, I85-204. 
MACLEAN, D. J. (1971). Studies on axenic cultures of the wheat stem rust fungus. Ph.D. thesis, University of Queensland, Australia.

MACLEAN, D. J. (I974). Cultural and nutritional studies on variant strains of the wheat stem rust fungus. Transactions of the British Mycological Society 62, 333-349.

MсСомв, E. A. \& Rendig, V. V. (1970). Some nonfermentable free carbohydrates in the leaves of canary grass (Phalaris tuberosa). Journal of Agricultural and Food Chemistry 18, 1092-1093.

MiersCH, J. (1973). Ribitol-14[C]incorporation in the ribityl side chain of riboflavin. Phytochemistry I2, I 595-I 596.

Mitchell, D. T. \& RoberTs, S. M. (I973). Carbohydrate composition of tissues infected by the autoecious rusts, Pucciniapelargonii-zonalis and P. malvacearum. Physiological Plant Pathology $3,48 \mathrm{I}-488$.

Mitchell, D. \& Shaw, M. (1968). Metabolism of glucose- ${ }^{14} \mathrm{C}$, pyruvate- ${ }^{14} \mathrm{C}$, and mannitol- ${ }^{14} \mathrm{C}$ by Melampsora lini. II. Conversion to soluble products. Canadian Journal of Botany 46, 453-460.

Nemec, J., KefURT, K. \& JARY, J. (I967). Thin-layer chromatography of aldonic acid lactones, aldoses and alditols. Journal of Chromatography 26, I $16-\mathrm{I} 20$.

Prentice, N., Cuendet, L. S., Geddes, W. F. \& Smith, F. (1959). The constitution of a glucomannan from wheat stem rust (Puccinia graminis tritici). Journal of the American Chemical Society 8r, 684688.

Reisener, H. J., Goldschmid, H. R., Ledingham, G. A. \& Perlin, A. S. (I962). Formation of trehalose and polyols by wheat stem rust (Puccinia graminis tritici) uredospores. Canadian Journal of Biochemistry and Physiology 40, I248-I25I.

Smith, D., Muscatine, L. \& Lewis, D. (I969). Carbohydrate movement from autotrophs to heterotrophs in parasitic and mutualistic symbiosis. Biological Reviews 44, 17-90.

TOuster, O. \& SHAw, D. R. D. (I962). Biochemistry of the acyclic polyols. Physiological Reviews 42, I8I-225.

Trevalyan, W. E., Procter, D. P. \& Harrison, J. S. (1950). Detection of sugars on paper chromatograms. Nature, London I66, 444-445.

Williams, P. G., ScotT, K. J. \& KuHL, J. L. (1966). Vegetative growth of Puccinia graminis f. sp. tritici in vitro. Phytopathology 56, I4I 8-I4I9. 